\title{
Spaces and places of remembering and commemoration
}

\section{Leanne Cutcher}

The University of Sydney, Australia

\section{Karen Dale}

Lancaster University, UK

\section{Philip Hancock}

University of Essex, UK

\section{Melissa Tyler}

University of Essex, UK

\begin{abstract}
Organisations engage in remembering and commemorative practices, often to produce effects of stability and continuity and to create shared meanings and culture, yet commemoration has been a relatively neglected theme in the study of organisations. The articles in this Special Issue range across diverse examples to provide a rich understanding of the dynamic and complex processes involved in the organisation of commemoration. In particular, they illustrate the importance of paying attention to materialities, spatiality and embodiment in the lived experience of practices of remembering.
\end{abstract}

\section{Keywords}

Commemoration, embodiment, places, remembering, sociomateriality, spaces

Recent research has emphasised both how commemorative artefacts and practices constitute culturally significant sites of meaning-making within contemporary social and organisational settings (Legg, 2007; Sargin, 2004; Sievers, 1994; Wasserman, 1998), as well as the extent to which commemoration is highly political in the ways in which it is embedded within, and reproduces, organisational power relations (Bell et al., 2014; Rowlinson et al., 2010; Sørensen, 2014). Yet with a few notable exceptions (e.g. Acevedo, 2014; Davison, 2010), commemoration continues to be a relatively neglected theme in the study of organisations. Commemoration is a widespread, seemingly benign aspect of culture and, because of this, perhaps one which we tend to take-for-granted as merely a 'background' or 'setting' for organisational life. Common commemorative artefacts, such as portraits of past leaders, become 'hidden in plain sight', as Guthey and Jackson (2005: 1058) argue. The papers in this Special Issue illustrate why it is worth paying attention to 
and thinking critically about the artefacts and spaces of commemoration, as well as exploring how processes of remembering and commemoration are organised. With this in mind, this Special Issue considers questions such as the following: Who and what do organisations commemorate, and how? How are spaces and places of remembering and commemoration organised and re-organised? What do organised commemorative spaces and places tell about whom or what is valued? What alternative spaces and places of organisational commemoration might be possible, and what political and ethical opportunities might alternative forms and settings of organisational commemoration open up?

Asking these questions about spaces and places of remembering and commemoration takes us to the heart of some recent concerns in organisation studies. In particular, they resonate with studies of organisational memory and how it is managed. Rowlinson et al. (2010) critique organisational memory studies for having a managerialist focus on the use of memory in knowledge management, thereby treating memory merely as a mechanical way of achieving the storage and retrieval of information. As they argue, this neglects the subjective experience of memory. It also focuses on individual memories, ignoring the social and historical context of remembering in organisations. Drawing on the social memory studies literature (e.g. Halbwachs, 1980; Olick, 1999, 2007; Zerubavel, 2003), they point to the significance of 'collective memory' (Halbwachs, 1980). As Olicks (1999) points out, 'It is not just that we remember as members of groups, but that we constitute those groups and their members simultaneously in the act (thus re-member-ing)' (p. 324).

Questions of organisational commemoration also connect to other themes of concern within contemporary organisation studies, such as subjectivity, embodiment, spatiality and sociomateriality. The very ability to maintain an experience of self through time requires memory over both the short and long term. Indeed, we respond viscerally to narratives of those who 'lose' their memories through illness or accidents, as films from Hitchcock's Spellbound, through The Bourne Trilogy, to the recent Still Alice illustrate. But memories do not only connect us to our-selves but also to others and to the world around us. In his phenomenological study of remembering, Edward Casey goes beyond the traditional perspective wherein memory is conceived as the property of human individuals, predominantly taking the form of mental recollections. Rather, he argues, remembering is social, collective, affective, embodied and contextual. He sees 'place memory' as pivotal: 'the fact that concrete places retain the past in a way that can be reanimated by our remembering them' (Casey, 2000: xi). Connected to this is the significance of 'body memory', since places, events and people are remembered with and through the lived body. But this is not solely related to the embodied individual, for Casey (2000) then turns to commemoration, where 'body and place memory conspire with coparticipating others in ritualized scenes of co-remembering'. We live in and through spaces and places of recognition and recollection, and we do this both individually and 
collectively. Therefore, understanding these spaces as embodied and embedded is essential. Here, it is worth pointing to Paul Connerton's (1989) classic study, How Societies Remember. He makes the distinction between 'inscribing' and 'incorporating' practices of memory. Inscribing practices are intentional acts, whereas incorporating practices are those in which memory is constructed through the repetition of physical actions. These latter may leave no trace as the former do, but become part of an individual's subjectivity and thus, for Connerton, are more effective in producing memory. Human memory is thus both individual and social in complex interactions of body, time and space.

Remembering and commemoration are not only social and individual, embodied and embedded, but are organised and organisational, although as Rowlinson et al. note, the significance of organisation for collective memory is neglected within the social memory studies literature. Organisations engage in remembering and commemorating practices. In particular, these can function to produce the effects of continuity, stability and longevity and also help to create shared meanings and cultures. Practices of remembering and commemoration are also organised: they are often deliberately structured in order to produce certain relations between the past (which may be reconstructed from a particular perspective) and the present, with the aim of influencing possible futures.

The temporal aspects of commemoration have often been recognised, but this Special Issue combines this with a focus on the significance of place and space, materiality and embodiment. In order to fully grasp the lived experience of the ways in which our relationship to the past can be organised, a concern with temporality is a necessary but perhaps not a sufficient condition. What is required is an appreciation of how the organisation of commemoration and remembrance is spatially as well as temporally constructed, how these spaces are enacted through embodiment and its sociomaterial entanglements and how relations of power intersect in complex ways such that spaces of commemoration are organised so as to become meaningful places that invite both reflection and agency. Let us deal with each of these in turn.

First, this approach connects to broader debates that have attempted to bring space back into critical organisational theory (Beyes and Steyaert, 2013; Dale, 2005; Zhang et al., 2008). Such spaces of commemoration and remembrance-and the ways in which they are transformed into places of meaning and agency-can, of course, take many different forms. These range from spaces specifically designed to foreground the past (and its implications for the future) such as museums and graveyards, to those that more subtly integrate the past into the living present in order to construct particular narratives of organisational legacy or progress, such as galleries of past leaders or single monuments to organisational heroes. 
It is, of course, not simply the character of the different spaces of commemoration and remembrance that concerns us here, as important as this is: it is the way that these spaces and places are enacted. Thus, a second area of connection is with the growing understanding of organisational life as embodied and embedded, and the recognition that organisations and organising are an inherently aesthetic endeavour. This requires an engagement with the materiality of organisational life-not just with material artefacts within organisations, which might be seen as part of the 'environment' or 'setting', but rather how sociomateriality is constitutive of organisation itself. In order for commemorative spaces to become meaningful places that might promote particular ways of thinking and doing, they must be produced, consumed and performed. This involves processes that themselves are mediated in and through relations of sociomateriality and those affective and aesthetic experiences they engender. This brings to the fore the need to consider the role of objects in shaping what Bell (2012) has termed the social construction of organizational memory' (p. 4). Here, we can see how the material commemoration of death-through artefacts such as corporate memorabilia, named or dedicated buildings and institutions, or even the broader spatial organisation of historical artefacts-is socially produced and embedded within relations of power and control (Willmott, 2000).

A third concern invites a consideration of the relations of power and control that determine who and what is commemorated and remembered. This relates to what Judith Butler (2004) has referred to as 'the politics of mourning': a politics that calls into question what 'counts' as a life worth remembering and is deeply embedded in the organisation of recognition and negation. Such a perspective could explain, for example, among other things, why commemorative sites are so often highly gendered or racialised both within the sphere of formal organisations and beyond. The politicisation of memory, the 'narration' of commemoration in Olick's terms, has rarely been the focus of critical reflection or inquiry within management and organisation studies. Yet, the question of how commemorative spaces are oriented towards the production of purposive memories through particular regimes of reflection and agency is an important consideration.

Having sketched out some of the relevant themes for thinking critically about places and spaces of commemoration, we now turn to the six papers in this Special Issue. All of these papers in some way draw attention to the dynamism of remembering and commemoration: their insights move us away from any view of commemoration which presumes a past which is fixed once and for all, either materially in commemorative artefacts or symbolically or in interpretation. This is some- thing which our first paper, by Matt Allen and Steve Brown, specifically explores through a discussion of what they view as contrasting 'preservation' and 'meshwork' models of understanding the processes of memorial organisation. Taking the spatial organisation-from conception to use-of the London Hyde Park memorial to the victims of the $7 / 7$ bombing as an example, they argue 
for the value in understanding memorials and associated spaces of commemoration as characterised by an ongoing process of becoming, or 'perdurance', that emerges from the complex and constant interactions over time between both human and non-human actors-people, landscapes, material and movements. As such, it is recognised that the meanings such sites have to both accommodate and bring forth are neither static nor officially sanctioned but are enmeshed in a living sea of shifting understandings, priorities and memories.

This processual understanding of commemoration is one which is also taken up in our second paper. Susan Ashley looks at the changing forms of memorialising related to the Chattri Indian Memorial, erected outside Brighton in the United Kingdom in 1921 in memory of the Indian soldiers who fought on the Western Front in the First World War. She argues that the memorial is not only a symbolic cultural object but also a focus of ritual and affective activity. It is very much a site which has become invested with embodied practices and meanings, which have shifted quite considerably over its history. In drawing on a postcolonial perspective, Ashley allows the interpretations and voices of marginalised groups and individuals to be brought into the understanding of this commemorative space. Reflecting on the work of Said and Bhabha, she considers how the original memorial reflected a binary construction of the colonial Other, in how it both referenced the colonial centre and also indicated a separating off of the Indian soldiers and their memorial from other war commemorations. Through an analysis of processes of de-colonisation and re-colonisation, Ashley shows how contemporary interpretations of, and ritual celebration at, the memorial is a hybrid form of memorialising which has the potential to disrupt and decentre the dominant colonial meaning through embodied, affective and collective practices.

The interrelationship between shifting power relations and spaces of commemoration is also at play in our third paper. Few modern political regimes have been as characterised by the extensive building of symbolic spaces and politically charged monuments as the world's Soviet-styled regimes. As Pablo Alonso González observes, this is no less true for Cuba, one of the few remaining communist states. However, as he also observes, such spaces often have earlier origins, commemorating for example the colonial struggles of the Cuban people before they were subsequently appropriated by the Castro regime. As such, Alonso González's article charts not simply the emergence of a single form of commemorative space, but rather the ways in which such spaces were constructed and reworked to renew political control under different regimes and professed aspirations. Taking the Civic Square, or Square of the Revolution, in Havana as illustrative, and focusing on the relationships between space, memory and state power, he unravels this dynamic relationship through a series of metaphors and conceptual frames that illuminate the importance of spaces of commemoration to the production of political subjects. 
These first three papers, by Allen and Brown, Ashley, and Alonso González, focus on specific memorials to provide considerable insight into the dynamic processes of how memorial spaces are organised and re-organised. In the second three papers, a subtle shift is made to the processes of remembering themselves, and how these organise and influence both the present and the future.

In the first of these, Fabio James Petani and Jeanne Mengis advocate a processual approach to Lefebvre's (1991) spatial triad of perceived, conceived and lived space. In particular, they consider how conceived space-that which is designed, planned and managed-comes into being not only through abstract plans and maps but also through shifting recollections and reconstructions, imaginations and interpretations of spaces and places in the past. Through their study of how a new cultural centre for a Swiss city is planned and designed, they show the influence of how memories of the past places and buildings on which this is to be constructed are brought into play in order to affect future decisions. As they say, following Lefebvre, 'these narratives of remembering are recomposed differently, thus creating from the past new possibilities for the future'. In doing this, they make a comparison to Proust's 'lost time', by suggesting the concept of 'lost space': 'a remembered space that connects a happy space of the past with the experience of its loss that narratively articulates the desire to regain, repeat or compensate for it' (p. 72, this issue).

Whereas Petani and Mengis show how memories which are selectively chosen and repre- sented influence the future organisation of space and place, Diane Rodgers, Jessica Petersen and Jill Sanderson show the political and organisational importance of that Other of remembering: forgetting. They do this through their analysis of 'Finntowns': relatively self-sustaining communities of Finns in North America in the 19th and 20th centuries. These settlements were particularly characterised by co-operatively run businesses, and strong labour and community organisations. In studying a specific example of a forgotten 'Finntown' within DeKalb, Illinois, they contrast the widespread local commemorative practices which celebrate the dominant capitalist entrepreneurial heritage with the alternative organisational and community forms of the Finntown that have been 'forgotten' and are not commemorated. The extant commemorative practices and artefacts in Dekalb reproduce and legitimise dominant forms of organising, while excluding the knowledge of alternative histories. This contributes to a severe limiting of possible present and future opportunities to organise differently. In their exploration of this commemorative remembering and forgetting, they develop Decker's (2013) work on silenced historical narratives and use multi-vocal antenarratives to counteract the dominant, exclusionary commemorative work. Their paper can in itself be understood as an act of re-membering, in offering a memory of these marginalised and silenced spaces. 
In our final paper, Scott Taylor and Emma Bell bring a number of these themes together in their study of the commemoration, memorialisation and what verges on beatification of Apple co- founder and former chief executive, Steve Jobs. Few figures in the contemporary corporate world have generated as much fanatical devotion in life as Jobs did, and it quickly became clear that this was a legacy that would not be allowed to be easily subverted in death. Invoking the concept of 'heterotopia', they consider the role that commemorative practices can play in the propagation of organisationally desirable regimes of truth and remembrance. Taylor and Bell focus in particular on the mobilisation of particular artefacts of memorialisation. They contrast what they describe as 'vernacular mourning' (spontaneous and temporary acts that are informal and not organisationally sanctioned such as shrines outside Apple shops and Internet communities) with formal corporate commemorative practices, including a closely controlled condolence book. They argue that whereas the vernacular rituals aimed to create temporary 'sacred spaces' where the continued presence of Jobs was celebrated, the corporate acts of remembrance were designed to promote an emotional acceptance by organisational members to the loss, in such a way that in 'letting-go' their mourning of Jobs, corporate survival beyond his death was ensured. In their analysis, Taylor and Bell help shed light on how managing the dead can, in turn, play a central role in the life of the organisation.

The papers in this Special Issue, drawing on a wealth of diverse examples, provide nuanced and thoughtful ways of deepening our understanding of the spaces and places of remembering and commemoration. They move us away from a fixed notion of commemorative preservation of 'the' past, to an appreciation of the dynamic and complex processes involved in remembering and the interaction of narratives and materialities woven together in the construction and reconstruction of these spaces and places. They analyse the multiple intertwined influences which come together in the organisation of remembering, such that we understand these commemorative spaces not as a simple reflection of relations of power but as intricately bound up with how they are lived, imagined and (re)interpreted.

\section{References}

Acevedo, B. (2014) 'Portraiture and the Construction of Charismatic Leadership', in E. Bell, S. Warren and J. Schroeder (eds) The Routledge Companion to Visual Organization, pp. 116-29. London: Routledge.

Bell, E. (2012) 'Ways of Seeing Death: A Critical Semiotic Analysis of Organizational Memorialization', Visual Studies 27(1): 4-17. 
Bell, E., Tienari, J. and Hansson, M. (2014) 'Organizational Death', Culture and Organization 20(1): 1-6. Beyes, T. and Steyaert, C. (2013) 'Strangely Familiar: The Uncanny in Organizational Analysis', Organization Studies 34(10): 1445-65.

Butler, J. (2004) Precarious Life. London: Verso.

Casey, E. (2000) Remembering: A Phenomenological Study. Bloomington, IN: Indiana University Press. Connerton, P. (1989) How Societies Remember. Cambridge: Cambridge University Press.

Dale, K. (2005) 'Building a Social Materiality: Spatial and Embodied Politics in Organizational Control', Organization 12(5): 649-78.

Davison, J. (2010) '[In]visible [In]tangibles: Visual Portraits of the Business Elite', Accounting, Organizations and Society 35: 165-83.

Decker, S. (2013) 'The Silence of the Archives: Business History, Postcolonialism and Archival Ethnography', Management and Organizational History 8(2): 155-73.

Guthey, E. and Jackson, B. (2005) 'CEO Portraits and the Authenticity Paradox', Journal of Management Studies 42(5): 1057-82.

Halbwachs, M. (1980) The Collective Memory (trans. F. J. Ditter Jr and V. Y. Ditter), vol. 48, pp. 1937-45. New York: Harper Colophone Books.

Lefebvre, H. (1991) The Production of Space. Oxford: Blackwell.

Legg, S. (2007) 'Reviewing Geographies of Memory/Forgetting', Environment and Planning A 39(2): 456. Olick, J. K. (1999) 'Collective Memory: Two Cultures', Sociological Theory 17: 333-48.

Olick, J. K. (2007) The Politics of Regret. London: Routledge.

Rowlinson, M., Booth, C., Delahaye, A., et al. (2010) 'Social Remembering and Organizational Memory', Organization Studies 31: 69-87.

Sargin, G. (2004) 'Displaced Memories, or the Architecture of Forgetting and Remembrance', Environment and Planning D 22(5): 659-80.

Sievers, B. (1994) Work, Death and Life Itself: Essays on Management and Organization. Berlin: Walter de Gruyter.

Sørensen, B. (2014) 'Changing the Memory of Suffering: An Organizational Aesthetics of the Dark Side', Organization Studies 35(2): 279-302. 
Wasserman, J. (1998) 'To Trace the Shifting Sands: Community, Ritual and the Memorial Landscape', Landscape Journal 17(1): 44-61.

Willmott, H. (2000) 'Death. So What? Sociology, Sequestration and Emancipation', Sociological Review 48(4): 649-65.

Zerubavel, E. (2003) Time Maps: Collective Memory and the Social Shape of the Past. Chicago, IL: University of Chicago.

Zhang, Z., Spicer, A. and Hancock, P. (2008) 'Hyper-Organizational Space in the Work of JG Ballard', Organization 15(6): 889-910.

\section{Author biographies}

Leanne Cutcher is an Associate Professor in the Discipline of Work and Organizational Studies in School of Business at the University of Sydney, Australia. Her research explores issues of identity and agency in relation to gender, space and age in organisations.

Karen Dale works in the Department of Organisation, Work and Technology at Lancaster University, UK. She has written about embodiment and organisations, most extensively in 'Anatomising Embodiment and Organisation Theory' (Palgrave 2001) and about architecture, space and social materiality as related to organisation studies, including 'The Spaces of Organisation and the Organisation of Space: Power, Identity and Materiality at Work' with Gibson Burrell (Palgrave 2008).

Philip Hancock is Professor of Work and Organisation and a member of the Centre for Work, Organisation and Society, at Essex Business School, University of Essex, UK. His research interests include the emotional, spatial and aesthetic dimensions of work and its organisation, the critical social philosophy of Axel Honneth, and the socio-economic and cultural organisation of Christmas. He has published in a number of leading journals including Organization, Human Relations and Work, Employment and Society.

Melissa Tyler is Professor of Work and Organisation Studies at the University of Essex. Her current work is on anti-narrative research, and commemoration and organisational subjectivity. 